\title{
The Impact of a Near-Death Experience on Family Relationships
}

\author{
Mori Insinger \\ University of Michigan
}

\begin{abstract}
This study explores the influence that a near-death experience (NDE) had on the family relationships of eleven NDErs, based on in-depth interviews. I detail the changes in relationships with extensive quotes providing data on family interactions. Analysis of the adjustments of NDErs within their family relationships reveals that while some families cope well and are positively influenced by an NDE, others may encounter difficulty and cease to function as they previously did. The transformation that NDErs themselves undergo, as well as the attitudes of others toward the NDE and the NDEr, are instrumental in altering NDErs' family relationships.
\end{abstract}

While the scientific explanation and/or interpretation of the neardeath experience (NDE) is still not unanimously agreed upon, the effect it has upon the experiencers is decided real for them. As sociologist William Thomas wrote: "If men define situations as real, they are real in their consequences" (Thomas and Thomas, 1982, p. 572). Previous research has shown that the NDE has a significant impact on experiencers. Raymond Moody concluded that:

There is one common element in all near-death experiences: they transform the people who have them. In my twenty years of intense exposure to NDErs, I have yet to find one who hasn't had a very deep and positive transformation as a result of his experience. (Moody, 1988, p. 27)

Mr. Insinger is with the Department of Sociology at the University of Michigan. This paper was excerpted and adapted from his seniors honors thesis. Reprint requests should be addressed to Mr. Insinger at 1819 Hill Street, Ann Arbor, MI 48104. 
It is this impact of the NDE on family interactions that I examine in this paper. This study explores the transformation that NDErs undergo, and the effects that this experience and transformation have on their family relationships. The NDE can have tremendous positive effects on experiencers and their lives, but can at the same time cause difficulties. Both aspects of this potentially life-changing event deserve further exploration.

I believe that this line of research is of great importance for several reasons. There are obvious benefits that a greater understanding of this phenomenon will have for clinical knowledge and use. The medical profession will be able to understand NDErs better as they cope with their experiences, both directly after them and as time progresses. This will ease the task of the medical community as it deals with an increasing number of NDErs, as biomedical science increases our ability to resuscitate individuals who might have otherwise died.

Clinicians and counselors will be able to assist the NDEr better as he or she has more time to react to, and gain understanding of, what has happened and the impact it may have. This will clearly benefit the experiencer, who may need and appreciate the knowledge, support, and understanding of counseling personnel. The family and friends of NDErs will also gain from the greater understanding of the impact of an NDE. This circle of relationships can be of critical importance in the life of an individual following an event such as an NDE. Better understanding here can facilitate an easier adjustment for all who interact with an NDEr, as well as provide greater insight into family relationships and friendships from a different perspective.

Furthermore, beyond adjustment in dealing with such an experience, there may be great value in the meaning that an NDE reportedly has for those who have them. Without putting NDErs on a pedestal, it may be that the examination and consideration of the way many of them attempt to live their lives, placing importance on the living of life in relation to others, is something from which others might benefit. I believe that the attitude many NDErs take toward living life, which admittedly is not unique to them, could make lives more satisfying, whether on a small or large scale; most people would be inclined to agree that consideration for others is a positive rather than negative attribute.

Finally, I feel that our understanding of death, in any capacity, is of importance to all who live. Indeed, many lives are lived in relation to their ultimate termination in death. If we can expand this horizon of knowledge and understanding, we will surely benefit in the knowledge 
and understanding of how we all live. This in turn may enrich not only our relationships with others, but also our own lives.

\section{Literature Review}

The field of near-death studies is a relatively young branch of science. However, as the field has progressed, studies have begun to focus more on the implications of the NDE for the experiencer, in addition to the growing body of research on the characteristics of the experience itself. It is the knowledge of this impact that the NDE has, especially on the family interactions of an experiencer, that this paper will expand upon.

Sociologist Charles Flynn (1982) discussed his preliminary findings on the implications of the NDE for the experiencer, pointing out common transformations such as greater concern for and understanding of others. Soon after, Kenneth Ring (1984) published the first major study focusing on the aftereffects of the NDE. In this work, he concentrated on the strong personal transformations and value changes that many NDErs undergo. Ring reported that NDErs generally had an increased love and compassion for others, including a greater understanding and desire to help. The second major research work to deal specifically with the aftereffects of the NDE was Flynn's (1986), which supported Ring's findings and remains the primary sociological examination of the NDE to date. Flynn investigated the impact that the experience has on NDErs, but he also began to explore how it affects their social interactions.

The beginnings of this exploration in greater depth have also been published in the writing of both P.M.H. Atwater (1988) and Barbara Harris and Lionel Bascom (1990). Atwater, herself an experiencer, detailed her research into both the positive and negative aftereffects of the NDE. Her work is among the first to deal candidly with the difficulties that an NDEr may have, in addition to the more positive aftereffects. Harris also addressed both aspects of the impact that her own NDE had on her life.

Both of these authors continue the current exploration into how the NDE influences lives, including how it affects the social world of those who experience them. The implications that an NDE has for one's family relationships will therefore be the focus of this study, as more intense qualitative, sociological research in this area is essential to a better realization and understanding of the significance of the NDE. 


\section{Methodology}

To examine the aftereffects of the NDE and their specific impact on family relationships, I conducted in-depth interviews with eleven NDErs. The sample was obtained by contacting researchers in the field associated with the International Association for Near-Death Studies (IANDS). These initial sources led me to contact the regional coordinators of Friends of IANDS discussion groups. I then was able to make personal contact with several NDErs to arrange for interviews.

My criteria for selection included that the informant had experienced an NDE, regardless of having actually been clinically dead, near death, or not; was willing to participate in the study; and resided within a driving distance from the University of Michigan that would allow for a one-day trip in which to conduct the interview. The resultant sample was not specifically designed to be representative, but rather to allow the collection of extensive detailed qualitative data. Ten of the eleven informants were female, while ages at the time of the interviews (range $=31-69$ years) and time elapsed since the subjects' NDEs (range $=3-28$ years) varied widely.

Six of my interviews with these NDErs took place in their homes, two were conducted through telephone conversations, one in the NDEr's office at work, one in a small restaurant, and one in a car as we drove to the home of another NDEr. All were sufficiently private, between the informant and myself, and during only one interview was there anyone else more than intermittently present; in that case, a few family members and close friends were present. Each interview was audiotaped.

I conducted the interviews as uniformly as possible, beginning and guiding them with the same general questions and probes. I did allow for digressions as they arose, while maintaining the integrity of research objectives throughout the interview. I strove to keep the interviews relatively informal, open, and comfortable, feeling this to be the best way to facilitate communication effectively. The emphasis was, however, on the NDEr relating his or her experiences, thoughts, and reactions to the interviewer; my role was primarily to guide the interview. The average length of the interviews was 90-120 minutes.

The interviews began with an explanation of research objectives and an assurance of confidentiality. The discussion then generally turned to an account of the subject's actual NDE, both in circumstance and description. The informant was allowed to explain this with as little interviewer commentary as possible. The interview was then generally guided toward discussion of relationships and interactions with others, 
along several different themes. Conversation was directed to explore relationships both before and after the NDE, including the changes and adjustments that took place. Both positive and negative aspects of the aftereffects were discussed in detail. After the completion of all eleven interviews, I made five follow-up calls for purposes of clarification and elaboration.

I analyzed the data by first transcribing all interviews. I then individually and thoroughly examined the transcriptions, and coded each part of the interview, theme by theme. I then broke down general themes into extensive subthemes, in an attempt to capture the many aspects of family interaction that may be correlated with the aftereffects of the NDE. Finally I disassembled the interviews, and reorganized them by thematic classification for presentation.

\section{Thematic Analysis}

This report will be organized into topical sections for the exploration of several issues relevant to family interactions of NDErs. The analysis will feature extensive quotes to utilize the data gathered in this study. The discussion will explore how families may react to an NDEr's experience, and how the NDE may affect an experiencer's relationships with his or her family unit as a whole, as well as with individual members of the family. For reasons of confidentiality, the names of all informants have been changed.

As is the case with the various elements of the NDE, the aftereffects of the near-death experience are difficult to generalize for all experiencers. The impact that an NDE has on the life of an experiencer is unique to each individual. While the findings of this study may in some aspects be generalizable, they by no means constitute an absolute or exhaustive report of the implications that an NDE may have for one's family interactions. The findings are more accurately the ways in which an NDE has affected the lives of specific individuals participating in this study.

In studying death-disrupted systems, sociologist Glenn Vernon (1970) reported that conflict is likely to occur in areas of interaction when prior planning has not taken place to form a set of expectations, in the case of an event such as the death of a family member. In a similar sense, the NDE of a family member is rarely, if ever, expected, and therefore might be likely to result in similar conflicts.

The conflict in this situation could be either heightened or lessened by the remaining presence of a member who might have been trans- 
formed by an experience such as an NDE. The survival of the member could be relieving for the family, but the possible aftereffects could on the other hand be disturbing. If the loss of a family member can require readjustment, so might the change in a family member's character. There may be a "social death" of sorts, when the familiar personality of someone dies, and the former behavior patterns that involved the experiencer may be disturbed. Indeed, change, whether in the form of a death or a drastic change in personality, could forseeably be troubling for others in a family unit.

While the study of these matters seems to focus on the potential for negative consequences, it is worthwhile to note that although the NDE can create difficulties in a family system, it is also a phenomenon with potential for dramatically enriching the relationships in a family. Whether it is in regard to their parents, spouses, or children, the family relationships that NDErs have are often affected to one degree or another by the experience. Indeed, the NDErs interviewed in this study all reported finding that their family relationships were influenced by their NDEs, in both positive and negative ways.

\section{Family Reactions to the NDErs Experience}

An event which has the potential to change someone's character significantly, can thereby have a variety of effects on the relationships of the family. One of the most critical issues in the family system of an NDEr who has just "come back" is the initial adjustment and acceptance that a family may have to incur. The family of an experiencer may or may not find it difficult to discuss and accept the NDE and its ensuing aftereffects on the experiencer.

After her NDE, Sue found that her parents were not very receptive to her explanation of her experience:

My parents-my dad-you can't talk to him anyway. He's got three subjects: golf, money, and Florida. They're retired now, but that's all he has lived for. So I have never ever tried to talk to him about my NDE, and I won't even try. Dad and I are like two worlds apart, communicating-wise, and my mom, she doesn't even believe in it. [She is quite familiar with] the books by Moody and Ken Ring . . . but she doesn't believe in it. I've shared my experience with her, how it changed my life, because Mom and Dad saw this big change in me. Here I was, this depressed person who stayed in her room with the music on, didn't go out, didn't do anything, until some really different changes. So they saw some changes, but Mom cannot relate them to 
that. She just thinks it was a suicide attempt, you know, (I got on medication, it lifted my depression), and saw the change, and she thinks my psychiatrist is the one who did it.

Sue's relationship with her father has apparently never been one with open communication. Therefore, it may be understandable that the NDE would not necessarily make it easier for her to talk with him, but Sue did express that she now had a greater willingness to communicate. As she explained, Sue has not found much acceptance of her discussion of her NDE with her mother, either. It is also apparent that even family members familiar with NDEs may not be enthusiastically accepting or supporting of an NDEr's discussion of the experience.

Cathy discussed her problems in trying to talk with her family about her NDE and the meaning it has to her. While they do acknowledge a change in her character, they are not eager to talk about or accept the NDE as the basis for her transformation. I asked Cathy if discussing her NDE with her family has at times been difficult:

Yes, in the communication aspect, very definitely. There is so much inside of me, and it's not an event that happened, once in your lifegone like a memory or dream, only to reflect upon whenever you want to. The experience became my life. It is who I am now, and with that, I want somebody to take that whole package.... If they reject my experience, they reject me.... I want the people closest to me to embrace my newness, who I've become, and this is very, very difficult to do, especially when you're trying to communicate something that sounds too weird. You know, for my family members, that are logically oriented people-who have for the most part never had any paranormal experiences occur to them, this all seems so silly and so foolish, to spend so much time focusing your attention on. So, I have learned to know when it's safe to say something and when it's not safe to say things, or just keep a lid on it. Communication is very difficult, because you're trying to explain something that for the most part, they have had no practical experience with themselves. You're talking about things that just are so out of the ordinary waking experiences, you just can't jibe. At first, I just said everything because I was so wound up-the experience, how I felt afterwards, all kinds of things. ... A lot of those kinds of things that I was sharing with my family, just didn't sound. . . and in retrospect, [laughs], I've got to be honest with you, if somebody said those things to me-really! They have the patience of angels, when I look back at it! I must have sounded like one nut. Now, I just kind of know what they're capable of listening to and what they're not. [Do they acknowledge that you are any different now?] Yes, that's very nice, they are very happy [but] they won't acknowledge that "Oh, that's because of your experience," because they have difficulty believing these experiences exist in the first place. They are logic-oriented, and just think I'm getting older, 
wiser, or something like that. You know, mellows you out a little bit. I'm not sure they even want to put a label on it, because to do so means that something did happen. . . . I tell them what it's due to, but right away I'm met with, "Oh, there you go again, talking about that stuff, that weird stuff again. That has nothing to do with it." They just think I changed independently, on my own, in the normal course of growing and changing; there is a very logical explanation for it, and you don't have to go searching for answers out there, it's very normal.

I asked Cathy how she felt about her family's inability to accept her NDE, and whether or not it has actually materialized as a problem in their relationship. It seems that although this is at times frustrating for her, she may just look at this topic as something that they do not agree upon or discuss at great length, and therefore does not feel it has been a great problem or conflict. Cathy explained;

It would be real nice for them to embrace it ... but there will always be that space between a nonexperiencer and an experiencer. It would be nice, but that's not reality. ... I can maintain a wonderful harmonious family relationship-very loving, close intimate family life, without need to dump this on them, and try to get them into my space. I'm much more relaxed in that. They need to be where they're at, and I'm willing to accept them on the level that they're at now; it really is okay. It's okay if my husband is an atheist and doesn't believe in God, it really is okay.... Prior to my experience, no way! I would have wanted to change them, mold them, manipulate them. . . to get them on my way of thinking or doing things.

So it appears that while Cathy's family doesn't openly accept her having had an NDE, they do acknowledge a change in her character, a change that Cathy explained is positively received. The experience is certainly important to Cathy, yet she is accepting enough of her family to not force them to discuss or believe what she feels about her NDE. While there is concern and love for those others in her life, and thus a desire to share the experience with them, there is also an understanding acceptance of who they are, not a desire to change them or their beliefs.

Other NDErs may at times find that the discussion of their NDE can be met with more than disbelief or a lack of receptivity. For some, talking about their NDE could be a source of tension and discomfort in their families. Some of the experiencers interviewed remarked that they felt that they really couldn't discuss their NDEs with their families, because it simply would have been more upsetting to them than anything else. Jenny said that her family really does not know much 
about her experience, because religion is not a very comfortable topic of conversation with them. She explained;

One of the reasons that I left home is because I wouldn't go to mass
and so this is the big breach in our family. It's like, "When are you
gonna come back to THE church?" and that's never going to happen,
so we don't talk about religion. That's why [my NDE] hasn't been
shared. Basically, it would just cause all kinds of, "What? Oh my God!
You've got to see a priest, or-I mean there would be some overtone of
Catholicism and that. I just really don't want to deal with-and I don't
think my mother really would believe me. That's why I haven't pur-
sued it.... We don't talk a lot. Our family is just not terribly
communicative.

In Jenny's case, it seems that the relationships in her family, especially in terms of open discussion, were already somewhat strained because of religious differences, so it is obvious why she would choose to just not talk about her NDE. That could simply make things more difficult. Furthermore, she feels that the reaction to her experience would be one of skepticism or even hostility. This too, would only serve to make matters more uncomfortable.

Pat expressed similar reservations about discussing her experience with the family she grew up in:

[On my own, I had become Catholic, so] if I went to the Baptists in my family and told them what I know, they would be very upset with me. They believe in Hell, and they believe in the Devil, and they believe in all these things. ... so it would upset their apple cart. They couldn't accept it. There would be no way they could, and I recognize that too, so I just don't push it. I don't discuss it with them. [How do you think they would react if you did tell them about your experience?] They probably would be afraid for me. They would be afraid that I had a contact with evil forces, if I went into it. It's not so much that I'm concerned what they think of me. . . I wouldn't hide [it from them], but I don't want to put a worry on them.

Like Jenny, Pat obviously refrains from sharing her NDE with these members of her family because of the difficulty it would create for them. She also explained that she doesn't avoid discussing it because she is worried for herself, but it is imaginable that some NDErs could feel pressured to not share their experience for that very reason. Some might feel that a family that would be upset, and even worried about "evil forces," would be too much to deal with, despite wanting or needing someone to talk with. This could certainly be troublesome for one who is feeling confused or uncertain about the NDE. It could serve 
to further alienate one who already feels a need for sharing his or her thoughts with an open ear.

The family of an NDEr could also simply not show much reaction at all to the experiencer relating the experience. Ann, for instance, found that her mother was simply reticent. While not being interested or supportive, her mother did not necessarily react negatively, or express any problems with it, either. Ann explained:

I told [my mother] about the experience, and we never talked about it again. She never made a comment when I first told her, nor later did she ever bring it up.

Some NDErs, though, find that their families are interested and supportive of the experience. Although Pat did not feel she could talk about her experience with the family that she grew up with, she found that her husband and children now are all very accepting of the NDE as a part of her life. Pat said:

[My husband] is a person who accepts me totally, and knows and understands the experience. He had four children, and they accepted it totally. My children accept it. I'm surrounded by people, in my everyday life, of total acceptance. I don't have anybody who is negative toward it.... So, I'm sort of cushioned in very positive surroundings.

In this environment, Pat has found it quite easy to discuss her NDE and her feelings about it, as it has influenced her life. It is a significant part of her life, and she feels fortunate to have such an accepting and understanding family. It should be noted however, that Pat had her NDE before she married her present husband, so the only way that he has known her has been after her experience. This might therefore have lessened the need for any adjustment that might otherwise have been necessary.

Unlike Pat, Mary had her NDE after having been married and a mother for several years, but has also found her family to be very accepting and understanding, saying:

I've had no problems with my family at all. I don't know that they said, "I believe you," but they never said they didn't-and they accepted it-whether they believed it or not, they accepted it.

While there was no apparent problem for Mary's family, with the occurrence of her NDE, it did necessitate some adjusting, some time to understand. Mary's husband explained: 
It took me a while, I think, really, not to accept-maybe to understand what happened. It wasn't that I disbelieved her. I just didn't quite accept all of it. And as we talked, and as time went on, yeah, I feel something happened there, something very remarkable. . . . I think I told [her] I did [believe her] after a while.

Mary's daughter was also present during the interview, and commented on her own reaction to her mother's NDE. She mentioned that because of having discussed NDEs in a course while she was in college, she was more easily able to accept and understand her mother's experience:

I think the reason that I did was just having had that course. If I hadn't had that course, I think I would have been in a different spotbecause it would have been such a foreign idea to me-but having had that and realizing that other people had it and all that stuff, it was kind of exciting. I think my concern at that time was when [Mom] told me that [she] was afraid we were going to reject [her] and I think that was what I was keying in on, more than saying, you know, that I was excited about it, or it was great, or whatever, because I knew it was real sensitive to [her] and that [she] wanted our acceptance so much.

As Mary's daughter suggested, a lack of familiarity with NDEs could make the acceptance and adjustment of a family group to an NDE difficult. When one member of a family experiences something as moving as an NDE can potentially be, the other members could easily feel confused or uncomfortable. For this reason, it is likely that the understanding and acceptance that Mary's family had for her made her sharing of her NDE easier than it might be for some others. Mary herself expressed sympathy for her family, similar to what Cathy said earlier, remarking: "If someone had told me this had happened to them, I don't know if I could believe it or not!"

It is evident that NDErs may have strong love and concern for their family, and that the experience may have a positive influence on their relationships. However, difficulties of some sort may also be inevitable after substantial changes in one member of a family occur, such as those that NDErs often undergo. It therefore seems that an attempt at mutual understanding of everyone in a family system can help make any necessary adjustments easier for everyone.

\section{Relationships with Spouses}

The relationship with a spouse is decidedly a significant part of an NDEr's link to a family unit, and could be strained and/or strengthened when an event such as an NDE occurs in the life of one of the 
partners. In some cases, relationships between spouses may encounter very few problems, or they may experience minor difficulties that can be resolved with patience, understanding, and adjustment. Others may find that an NDE makes a marriage impossible to continue. Regardless of which is the case, most married NDErs are in agreement that their relationship with a spouse is substantially influenced by the NDE.

Some of the NDErs in this study found that after their experience, the ensuing difficulties in their marriages could not be worked out, and thus led to divorce. Flynn remarked that although "no exact data are available on the rate of divorce among NDErs as compared with the general population ... other researchers and I have informally observed . . . a relatively high divorce rate among NDErs" (Flynn, 1986, P. 24). It is certainly not valid to assume, though, that divorce is inevitable.

Pat's marriage to her first husband ended several years after her NDE. She mentioned that she thinks they were probably destined to be divorced eventually because of his psychiatric problems, but that she remained in the marriage for a while, hoping that things could be worked out. Although this relationship did end in a dissolution that was seemingly not resultant of Pat's NDE, I found her discussion to be significant because of her relationship to this former spouse while they were still married. It is apparent that her NDE had a significant effect on her relationship with this man, because of the way she felt toward him despite the problems they were having.

Pat explained her former husband's problem:

I went to a psychiatrist because of my ex-husband's problem as a child molester. ... I had to watch my children very closely. I caught him before he actually harmed them right in the beginning stages, I caught him right away, thank God ... So, I went to the psychiatrist and protected my children faithfully, but the psychiatrist asked me, "Why do you stay with this man?" and I said to him, "This man has many fine qualities." Unfortunately my husband didn't follow up on visits - I couldn't stay in the marriage. ... I suffered the consequences mentally, there, knowing what I was doing, and I thought this is no good, I can't do this.

Pat's compassion for this man in this situation is extraordinary; most people might not have had any patience for such a person. She went on to relate the extent to which she was tolerant of his problems, which further illustrates her extreme understanding and concern for him, despite the consequences it had for her and her children: 
I can't tell you there wasn't any friction [in finally separating] because there absolutely was, I did harbor feelings, and still do, of dislike. I think there would be cause even to do physical harm, in my mind, if I hadn't had this [experience]. There were so many opportunities to do physical harm, that I could have done, that I didn't do. . . . [There was] one incidence of physical violence that my husband inflicted on me, and it was very dangerous, and it was very physical, and it could have hurt me badly - and there were knives right near me-and I knew they were there. I knew I could pick them up, and that I could use them and stop the abuse and possibly no one would have condemned me for it, but I took the abuse, and I carry the bruises and the scars to this day-from the physical violence. [Before my experience though], I probably would have defended myself. . . . I didn't put him in prison, I could have done that, and one of the reasons I didn't put him in prison is the fact that I knew what they would do to him in prison; he wouldn't get any help.

The understanding and love that Pat showed for her former husband is nothing short of remarkable. Not only was she tolerant of his infliction of mental and physical abuse on both their children and herself, she also maintained a genuine concern for his welfare. She recognized that she could have taken several courses of action, but continued to try to deal with the situation until the dissolution of their marriage. Still to this day, she does not use the word "hate" with regard to her feelings for him. Pat explained that she attributes her tolerance and understanding for this man to her NDE. She described the love that she feels for people, including him, in a way similar to what several other NDErs said about someone who has been hurtful to them:

[How does the love that you felt in your experience affect your relationship with someone?] It doesn't allow me to do anything purposely to hurt another human being. There can't be any revenge to anything that anybody does to me. . . Even if that person has hurt me ... [to hurt them back] goes againgt unconditional love. I was shown what unconditional love is; I was given unconditional love, and once that happens, you just can't do it, you just can't deliberately hurt another human being.

In feeling this sort of love for people, because of her experience, Pat found herself to be unable to hurt her former husband intentionally, and was instead extremely compassionate and understanding. It may not be that all NDErs feel such understanding to this limit, but Pat is by no means alone among NDErs in the strength of her convictions. This sort of behavior may be incomprehensible to those who do not easily understand the unconditional love that NDErs describe. Some 
people may feel that NDErs are simply näive, in the sense that Atwater (1988) mentioned, with their acceptance of others. Indeed, this may be how some view the attitudes and actions of some NDErs. Regardless, many NDErs feel certain of the absolute goodness of behaving out of unconditional love with everyone, including their spouses.

Pat's second marriage has apparently been much more successful than her first, and she talked about her relationship with her present husband. She explained how she felt after her dissolution from her first husband, before she met the present, saying she prayed that if there was to be someone in her life, he would have to be "brought to her." That, then, is how she feels she met her current husband, saying, "It is a long story, but he appeared ... and kept coming back." Since then, she feels that this marriage has been very successful, remarking that her husband is very accepting and understanding of her, commenting that "In every aspect of my life, this person that I married has more than fulfilled every need, so it worked out very well." As previously mentioned, the fact that the two met after Pat had her experience may have made things easier than in some NDErs' marriages. There may not have been the adjustment that a family might normally undergo when one member has this suddenly life-changing experience.

Pat admitted that as with any marriage, there are times when she and her husband do not agree on everything. When this occurs, she explained, her NDE is a great influence on how she deals with the situation. She discussed a recent conflict, where she felt one way about something, and her husband felt another:

I was able to get really quiet, and . . . go back to the area that I was in when I had the NDE. Now I can't go back as far as I did . . . however, there is an area that I can get into that is almost like the beginning of the NDE. It's a very deep meditative state, to a part where you have contact with either your higher self, or with God speaking through yourself. So when I went into this meditative state and I wanted to know what to do, "What should I do?" and the answer I got had nothing to do with what I should do at all. [Instead], it gave me total understanding of what was going on from [my husband's] viewpoint, and made me be totally understanding of what his side was . . where he was coming from. . . . that there was a fear behind it. So, when you find that person's fear, then you understand where they're coming from and there's no need for the confrontation-so there's more understanding.

Pat went on to say that she felt that before her experience, it was easier to understand where she was coming from, and she found it hard to "release herself" from her own needs. She also mentioned that there 
has been one specific matter that she and her husband have at times had difficulty with:

The only thing that I can say that [my husband] has had a problem with me is my lack of regard for money. I have absolutely no concept or regard for money ... and so if I have money, Im happy. If I don't have money, it makes no difference to me, so he keeps track of all the finances in the family. I'm fortunate at the moment, that things are fine, and I suppose if I had to, I could, but I just don't have any regard for that, for money, that way. ... It took him a while to understand that I have no regard for money. If somebody needs something and I give it, he says, "Well, did they pay you back?" and I say, "I don't remember-it doesn't matter. It took him a while to understand that. . . . So, I get an allowance, and when I get that, it can go anywhere, and he knows that.

A problem of this sort can be difficult, when the two may have conflicting values that they feel are important. Indeed, both Ring and Flynn commented on such matters, saying that they found most NDErs place less value on money and material things after their experience (Ring, 1984; Flynn, 1986). Value changes of this nature can thereby be troublesome in a partnership such as marriage. It may take time, patience, and understanding to resolve such conflicts.

Like Pat, Dorothy also found that her first marriage could not continue after her NDE. Dorothy however, is more apt to attribute her divorce to the NDE and her resultant change in character. She feels that the transformation after her experience was too drastic for her former husband to cope with. She explained that he just could not understand her new personality, because it was not what he had been used to or comfortable with. She said he would complain that she was "expounding all of this about seeing the Light, seeing dead relatives, and about all of these changes [that had occurred in her]" and that he would say. "Give me back my wife!" Dorothy explained, "You just can't do that." Furthermore, he could not accept what he would describe as her "talking about Heaven and God and Light and Hellish situations." As much as NDErs seemingly do not want to hurt others, they might feel so strongly about the very matters that their spouses have difficulty with, that they may have to end the relationship. In Dorothy's case, the relationship became so difficult for her husband that they eventually were divorced.

Although Dorothy is now happily remarried, she remarked that there are still occasional difficulties. Saying that "It can be hard for people to get around materialistic values," she explained that her 
husband sometimes has trouble with her generous nature: her frequent long-distance telephone calls, or her travelling out of her way to help someone with something. As an example, Dorothy was kind enough to take a weekend trip to meet with me, and to introduce me to another NDEr. As Dorothy pointed out, he might remark: "What are you getting out of this trip?" Again, the generous nature that an NDEr such as Dorothy exhibits for so many others might be troublesome for a spouse who is not used to that sort of behavior. She feels that it is simply hard for her husband to accept her always helping others. I asked her how she decides what to do, knowing that her husband might be either angry or hurt at times. She responded:

What I feel in my heart, that deepest instinct in me, that's what I follow and have to do. ... Sometimes you have to let [those concerns of others] roll off of your back, because if you really take it personally, it can hurt. Other times, I ask God to help him understand. I've told [him] that I have to do what I have to do ... and my whole thing is reaching out and touching, being a part of someone's life helping someone else through whatever.... It's not easy to explain that to people-you have to hope that with time they will understand it better.

Dorothy explained that she does not resent her husband's difficulty understanding her, or try to force him to change. She said:

[He] cannot always understand [my having to do what I do], but that doesn't make him less of a person.... We don't necessarily agree on things, but this is his space, his understanding, so I leave him in that. If we find something that, between my world and his-there is a bridge there-then that's great.... differences aren't any heavier, they just change focus.

Thus, Dorothy accepts her husband the way he is, which is perhaps the way NDErs would ideally like to resolve their differences with others. None of the NDErs that were interviewed in this study indicated any strong desire to change others, including those closest to them. They might be eager to share a part of themselves, but did not indicate any desire to direct the lives of others. Interestingly, though, Dorothy mentioned that she has known some NDErs who seemingly have wanted their experience to be meaningful for their spouses, saying that they "may feel it is [their] place to help in the spouse's transformation, not understanding that each person's transformation ... comes to them on their own." 
It is also notable that Dorothy commented that the problems that she and her husband have are not necessarily any more difficult than problems before her NDE; they are just problems of a different nature. Nevertheless, they need to be dealt with, and Dorothy related how she has tried to assuage her husband's concerns:

I told [my husband], "It's not that I love you any less, I've just been given a greater capacity for caring ... and [if I] share that caring with someone else, don't think that's being taken away from you, because it's not. It's just that I'm being spread a little thinner." That doesn't always satisfy their need though. ... It is hard for him to deal with sharing Dorothy's time. [Does this "being spread thinner" mean diminished quality to others, though?] Right, I don't see it as diminishing. He may see it as diminishing, but then on the other hand, if I were home today, [he's] not home, he's working someplace ... so what good am I going to do sitting at home in an empty house?

Obviously, this situation can be hard for both partners in a relationship to deal with effectively. They may both feel very strongly about their positions. NDErs may feel that they do indeed "have to do what they have to do," but still love their spouse just as much as ever, as Dorothy said. Spouses on the other hand may feel that the person they married has drastically changed, or is no longer as devoted or loving a partner, as he or she was before. It is foreseeable that with some people, feelings of jealousy or abandonment could certainly arise.

Atwater (1988) mentioned in her research that NDErs and their families may at times not have the same perception of their relationship. She described NDErs who felt they were so much more loving than before, yet their families did not perceive the kind of love that the NDErs felt they were giving. Atwater remarked that while her own daughter thought "Mom" was more understanding, she "was no longer personal, familiar, or even lovable" (Atwater, 1988, p. 72).

Similarly to Dorothy, Beth also divorced after her NDE, finding that her husband could not cope with the changes in her character. Beth explained how she feels she was a different person after her experience:

I was suddenly in touch with my emotions, (emotion was something that was never shared in the family before), and all of a sudden I'm getting emotional, over good things-seeing the beauty in life, seeing quality in so many things that [my husband] didn't consider valuable, and his values were still very materialistic-businessman, enjoyed gambling, enjoyed status, (everything was based around status 
seeking)-and that wasn't important to me anymore. I wasn't his partner, in that end of it. . . . I [could understand him], but he couldn't understand why I wasn't supporting what he thought was important. Like if we took a vacation, it would have to be something centered around-like on a cruise-gambling, and that wasn't romantic to me, and I wasn't playing the role that I had played before; I wasn't supportive of that. In the last three months we were married, he finally insisted we go into counseling-I had asked him for years, and all he kept saying was "make her go back to the way she was." . . For a long time, I felt very guilty that I had changed. It's taken me all of this time to realize that I'm a human being and I deserve to change. His whole thing was that I was wrong, because I had changed. . . . He wanted somebody that was dependent, and I think my [new] selfesteem was threatening to him.

Clearly, Beth's husband found the change in her very difficult to deal with. The familiar partner that he had for many years was suddenly a different person in his eyes. In this sense, his reaction was similar to that of Dorothy's first husband, but as Beth explained, her husband was not upset simply that she was different. More importantly, she no longer valued the things that he did. Beth also suggested that another part of the problem may have been that he was used to a more dependent wife, and therefore felt not only alienated by everything that was suddenly important to her, but also challenged by her new personality.

Interestingly, the reactions of both Beth's husband and Dorothy's husband are similar to what psychologist John Bowlby described in his research on mourning. Bowlby (1961) suggested that if an interaction system such as a family focuses on the loss of an original member, such as an NDEr having changed from the way he or she was before the NDE, this can result in grief and disappointment. He also pointed out that if the interaction system continues to do so, there may also be anger to regain what has been lost. This may be what these two husbands were, in a sense, doing after their wives' personalities were transformed by their NDEs.

Beth is not married at this time, but briefly shared her feelings about her present relationship with another man. She commented:

I'm in a relationship now with a wonderful man and we just really complement each other. We're both still very aware of our weaknesses, and each other's weaknesses, but that's okay; we're supporting each other's growth and supporting each other spiritually. It's not a threat, his growth and his spiritual expansion isn't a threat to me and neither is mine [to him]. So, now I'm creating healthy relationships. 
Beth explained that she came to value relationships, getting to know and helping others, after her experience, and that this was also troubling for her former husband. She expressed much more satisfaction with the relationships that she has been in since the NDE, being involved with people who understand and accept who she is. As she mentions here, her relationship is complementary, and not threatened by her growth and spirituality.

The relationships that NDErs are involved in can become deeper and more meaningful on several levels. Beth also discussed how intimacy and sexuality in a relationship may be affected by the NDE. She felt that intimacy has changed in her relationships, becoming more enriched, saying:

It all changes. There is a much greater gamut, from $\mathrm{A}$ to $\mathrm{Z}$, once you've had the experience. . . . I functioned . . . until I had my NDE [in my thirties] in a state of numbness, as far as emotion went, okay? Well, numbness is the bottom of the scale. You know, you go straight on up, and on the top is unconditional love. Well, I'm still human. Unconditional love is still a hard one, although that's what I'm hoping to achieve, but there's a whole big, long ladder now to climb-from numbness to unconditional love. Well, that goes with sexuality, too. It's not just one rigid area anymore. There's playfulness, right on up to spiritual love, and somewhere above or below, I don't even know anymore, because there is no above and below, there's just all around-but there's, you know . . . just sexuality for the pure sake of two bodies merging, but there's also playtimes and there's also some real devoted spiritual aspects of sex, too.... [It's] incredibly more enriched, and okay to not be there at all.

Somewhat conversely to Beth, Emily was not married at the time of her NDE, but has since been married. She explained the relationship she had with her significant other before her experience, and its breakup afterward:

When I had my experience, I had been living with someone for two years and we had a sort of iffy relationship; we didn't know if we were going to get married or not, but after my experience, we absolutely could not relate to each other in any way, shape, or form. He was a very strong person, but he lacked that inner strength, that kindness. I became a totally different person, [more independent]. I did, I had a complete 360 , because I had . . . been divorced before, and I met thim, the person I had been living with when I had my experience] and he was real strong and independent, Type A, real similar to me; we could be two totally separate individuals. We were making lots of money 
and spending it just as fast. You know, lavish vacations, fun times, lots of drinking and partying, and all that stuff. After I had this experience, I became real introverted, real introspective, a complete 360. Number one, that was a real detrimental thing to him. I mean, I was still fun, I could still do those things, but it didn't mean a whole lot to me. It wasn't fun anymore to go out and get totally drunk or do lots of drugs-I mean, we had lots of money so that's what we did-and all of a sudden, those things weren't important. So, I didn't fit into his lifestyle anymore, and I became inwardly much, much stronger. . . . I felt absolutely no guilt when I left, although it was very important for me to maintain a relationship with him on a friendly basis, and that was real hard for him when I left . . . he didn't want me to leave at all, and $I$ had to, because it just didn't make any sense. . . . his priorities were totally different than mine. I didn't care if I had a lot of money and I didn't want to go on those expensive vacations. . . All of those things that I had done before, I became more anti-social, and I was like a real Miss Socialite before.

Emily felt that she and her former partner were no longer compatible after her experience, finding that they were no longer interested in the same things. Emily also noted later that although her boyfriend did not necessarily want to end the relationship, he did have difficulty with it after she had had her NDE and was trying to cope with its impact:

After my experience, I would have dreams about people-the whole psychic thing was a very, very strong part of me not understanding what was going on, and that was a big part too-that scared my boyfriend that I was living with at that time, that frightened him. Things like that happened all of the time, and that was very difficult. I mean, he was like, "I don't want to hear about it! If you dream about me, don't tell me anything!" and that was very difficult in our relationship, because I didn't know why I was having all of these dreams. I didn't even relate it to having the experience, but then as I looked back and as I started to gather information, I realized it started right then, from that point forth.

Emily mentioned that the period after her NDE was difficult at times for her, saying that she was just boggled and didn't know what was happening to her: "You really do think you are going crazy!" On top of all of the confusion and uncertainty she had in her own mind about what was happening, she also had to deal with the frustration of her boyfriend and her feeling that they no longer had similar interests. This then led to their breaking up.

Emily is now happily married, and although she did meet her husband after her NDE, she tried to explain how this relationship with a significant other differs from those in her past: 
I feel like my significant other is the Light that I have inside of me. I feel like that is truly my significant other, but as far as my relationship with my husband. . . . I think for me right now, it's a need that I have someone to share my life with and he's real strong, he's one of the kindest people I've ever met in my life. Even though he doesn't agree with any of this, he doesn't even actually accept it, but he lets me be myself and he stays out of it. . . . He doesn't understand what I am doing, he doesn't understand how I feel, he's not supporting in any way, shape, or form, but he just lets me do what I want to do, and if that's important to me, then I can do it.... He's not the jealous, possessive type of person, just very strong in his own individual rights and I pretty much am too. I think that's the reason we were able to be together, and that's the only reason.... It was discussed in length before we actually got married that I could not change my spiritual beliefs although I know it's real important to me that he continue to believe the way he does. It was important that he not influence me in any way; he needed to be supportive-just let me do what I have to do. ... [He just lets me be myself, in that respect], but on every other level in my life, he's the kindest person I've ever met. . . Although you never know what's going to happen. . . . I know that spiritually, if nothing else, he will always be a part of my life, just because there's that emotional bond somehow, and it isn't sexual. My other relationships were highly physical relationships, and that was my bond. This is very different, not to say that it doesn't exist, but that is absolutely not the basis. That is unimportant, what happens to us physically. There is something else there, and that I don't really know how to describe.

Interestingly, Emily mentioned feeling that her bond with the Light is her foremost relationship with a "significant other," illustrating the personal and enduring nature of the NDE on her life. Feelings like these could be difficult for some spouses to understand, but it does not appear to have been any problem in Emily's marriage. As for her discussion of her relationship with her husband, it is apparent that an agreement on an NDEr's personal attitudes, beliefs, or way of life is not absolutely necessary for a marriage to be successful. As Emily pointed out, even a lack of real support or understanding of what she does is not a problem. She finds that although her husband is not enthusiastically interested in her NDE and its meaning to her, their mutual ability to be nonpossessive, nondirective partners makes the marriage work. Their discussion of their independence and individuality before the marriage is also of significance. With open consideration and respect for one another, this marriage is seemingly what both partners need in their life together. It is also interesting to note that Emily now finds a physical, sexual bond is not the basis for the relationship, the way it was for her in the past. The physical aspect of 
the relationship is still there, but "unimportant" compared to the emotional bond that truly links her and her husband together.

While some NDErs do find frustration and difficulty of varying degrees in their relationships with significant others after their experiences, other NDErs remain in their relationships, without much difficulty at all, or by working things out together.

Mary felt that she really hasn't had any problems with her marriage; her husband has been very supportive, understanding, and accepting. He commented on their relationship since her experience, explaining that sometimes he felt that he needed to help her keep a perspective on what she was doing. Speaking of Mary, he said:

I think there's been a big difference in her since her experience. I think she has a greater spiritual realization, a deeper one, and I sometimes think she takes everybody's problems on her own shoulders, and this gets to be a problem sometimes; she gets too involved and everything.

In talking with Mary's husband, it was clear that he did not make this comment out of jealousy or resentment. Rather, he explained how Mary might become so involved with others, that it would start to cause inconvenience or problems for herself, and that sometimes she might not even realize it. He also spoke specifically about the relationship between them, saying:

\begin{abstract}
Between us, there's been a difference. We've grown a lot closer since this experience ... before she would have been there if you needed her, but after the experience, you didn't have to look around to see if she was there-she was there, and she's been a big help to me.... I won't say that it's been an interference in any way. We've worked together and, well, we always have, worked together to do things, and there's a little shifting back and forth of responsibilities, but if anything, it's brought us closer together.
\end{abstract}

Mary's husband feels that she has been even more supportive of him since her NDE, and that any adjusting, in the way that they always have, has merely brought the two of them closer to one another. This is seemingly a very successful partnership, because of the mutual support and understanding of Mary and her husband, both before and after her experience.

John found that despite some minor adjusting, his marriage has also continued successfully. He explained that his change in character has 
at times been difficult for his wife, because it is so hard to understand what happened:

She was right next to me, and I told her I loved her and I closed my
eyes, and something happened, and I've been a completely different
person ever since then. . . She knows that I was gone-not out of the
room, or out of my body-I mean gone to a place that she can't even
imagine. She knows how much I changed ... - and what happened?
There is no logical explanation. I don't even know, "Where is there?"

John also mentioned that it is somewhat difficult for his wife to accept his decision to change careers in the middle of his life, going from his successful role as a tenured professor, to a career in the ministry. He continued, pointing out that marriage itself is a relationship characterized by occasional struggle; there just may be different hardships after something like an NDE. John elaborated upon this:

[My] marriage is good. ... . everything has worked out fine. I get along well with my wife, we're happily married. Like any marriage, there have been struggles. For example, I used to be very jealous, now I don't have any jealousy - well, significantly little jealousy. I used to be really controlling, now I'm less so. In those sorts of things, in a lot of respects, I'm a lot easier for her to live with; I'm more considerate... Now, we have difficulties because I think we need to communicate better, because I feel there is a barrier between us. Before, I never said stuff like that. When you become more sensitive to other people's needs, the problems don't necessarily go away, they may be magnified. [Has that sensitivity made it any harder for the two of you to get along at times?] No, it's made it easier, because I can be more empathetic.

What John mentioned about the change in difficulties that a marriage may encounter is important to understand. Like Dorothy, he feels that the relationship merely has new issues for both partners to consider. John pointed out that even what might generally be considered a positive change in character, such as a greater sensitivity to the needs of others, can bring about new difficulties that may or may not be any greater than before. While John does feel that overall the relationship has indeed improved, there are nevertheless still some matters that require resolution.

Cathy also found that her experience has generally been a very positive influence on her marriage. She explained that her relationship with her husband has been strengthened by her NDE, through the 
impact it had on her and the way she views him. Elaborating on this, she said:

[The relationship between us is different], very definitely. Before my experience, I was always feeling that he had to live up to my expectations, in order for me to be happy in my marriage. I was carrying a big load, working, kids, and family - the whole thing and I wasn't getting any help from him, no emotional or physical input at all. So, I held an awful lot of resentment, and because of the resentment, I felt that $I$ had to retaliate ... so there were ways that I could get back at him, so to speak. I wasn't very happy. Following the experience, however, I mean we're talking instantaneously -as soon as the experience happened and was over with-I was totally a different person. I saw my husband through eyes of love. I saw him as the same person that I am at the core of my being, and the same way that every human being is at the core of their being as I experienced it, and with so much love, I just saw all of his character flaws disintegrate. They were there, the flaws were still there, but, it's as if they didn't have the same kind of meaning for me anymore. I let him be who he was, and embraced that. I got off of his back; I just didn't complain anymore and harp on him the way that I used to. I found that I was more relaxed, and I'd do little things for him and I found out that he started to return those things for me-in return, started doing little nice things for each other.

The love and acceptance that Cathy felt during her experience apparently affected her strongly, leading her to relate to her husband quite differently. She applies the love that she was given in her experience to her relationship with her husband, by accepting him for who he is, no longer trying to change him with complaints about what she didn't like about him. She sees him with the same compassion that she was finally able to see herself with. Cathy mentioned that her husband finds her to be more understanding and easygoing, and he, in turn, is more appreciative. The kindness that she gives him is thus returned to her, enhancing the relationship for both of them. It is interesting, though, that their closer relationship does not necessarily mean that her husband accepts the experience itself. Cathy explained how he views the reason for her change:

He's at the point now, where he's saying, "Well, I can say that something probably happened to you -I don't know what happened to youbut it doesn't make any difference to me, what it is. It's meaningless to me. I have no interest in finding out what it was, but there's probably some kind of logical explanation for it-it's not this paranormal stuff." He notices that [I've changed], but he doesn't want to acknowledge [an NDE]. 
In talking about the impact of the Light and its love on her relationships, Cathy said that she views everyone as part of the light, and that is why she is able to "genuinely care about [everyone] at such a really deep level." The ensuing discussion around this matter illustrates the difficulty that this love may present, in both explanation and understanding:

[So do you start to relate to everyone almost the same way?] Yeah, I do. [How is your husband different than other people then?] Well, I feel so special in knowing that he was the one that chose to be with me, to nurture me, to love me and provide a home, and to have children together. He could pull out any time he wants to, but he doesn't. ... He's really a neat person; I can see him as a true friend. [So is he more special than other people because of the way he feels for you?] Oh sure, yeah - but no-not because of the way he feels for me, is he any more special than anybody else, because my love for him is unconditional. It doesn't matter. I think that's why I can love him as much as I do, even though he thinks I'm weird or crazy. ... I don't take it to heart. Probably because in the greater plan of it all, somehow we were brought together, and we were meant to share this life together and we chose to commit ourselves to one another. I don't know, I guess I just see him as a wonderful being of Light, but is he more special than somebody else? I would like to say that I love everybody equally, the same, but that wouldn't be the truth, in one sense-in another sense it would be the truth....

Needless to say, this love that Cathy describes might be quite difficult for many to understand. An outside observer may find it hard to comprehend how this love for everyone is possible, thinking of love in the more familiar terms of a personal, subjective love. A spouse, on the other hand, might be more disturbed, feeling less important, jealous, or simply confused and alienated. Perhaps this unconditional love cannot be fully understood without experiencing it, as NDErs point out. Either way, it is a love that NDErs may apply to their interaction with others, regardless of who they are, feeling that they love everybody and truly mean it, as Cathy did; for it is this love that NDErs most often find an undeniable aspect of the NDE. While it may make communication and understanding difficult at times, it also has the potential to make a relationship closer and more meaningful, as it has for Cathy.

Cathy explained that there has been one difficulty in her marriage, though, as a result of her NDE. Like Pat, Cathy's "problem" involves her decreased interest in money. She explained: 
Prior to my experience, I worked for 20 years as a cytologist. . . . I did research work and clinical work, and my husband was always very insistent that I work - a two income family. Following the experience, however, it became very, very increasingly important for me to stop working, and leave that time open for my "real" work, which was the work that the Light told me to do during my experience-basically it's to become a communicator, to share what I know - any form of communication. So I thought, I know on one hand that I'm helping my fellow human beings; I'm helping to save lives by early diagnosis of cancer and things like that. At the same time I am contributing to the support of my family, those are very noteworthy reasons for working, but inside, I just couldn't do it anymore; I had to do my "real" work that I was told to do when I came back. So, I made a decision to quit work and this upset my husband very much, and he was very worried about how we were going to manage on one income, but I just had to do it. It took me maybe a couple of months for him to get adjusted, then after that, he said very, very little about it, and I just started [working with people, lecturing, giving workshops, etc.]. Then last year, I decided to go back to work again, for only one reason. The fellow who owns this lab was in danger of going under, because he had a two month backlog of cases . . . consequently the doctors were pulling away. ... so he was at the point where he had no other option than to send up an S.O.S. and [ask me to come back to work]. I didn't want to come back to work so he told me the situation and asked me when I could start and I said, "I'll be over in an hour!" I got him all caught up. I felt so wonderful for helping him. It had nothing to do with the salary I was earning, or anything like that; the whole staff would have been out of jobs, but I got them back. Oh, I can't tell you what a great, great feeling-but in [a few months] I am going to retire... [and my husband] is already starting to say, "You know, you've got to find something else to do; you have to do something," and he's right. When you look at the figures, on paper, there's nothing for our retirement. I should be very concerned about it, but the truth is, if you want the truth, I'm not.

It is interesting to note that Cathy acknowledges the value of her work as a cytologist-that it was helping others, including her own family-but still chose to do other work, which she felt was more important to her. She found it important to chose work that still allows her to help others, but in a more personal manner. It may be that talking with people is merely a better way for Cathy now to help others. Even if the NDEr comes to feel comfortable with what he or she does in life, a problem in a relationship may remain. A spouse may continue to have difficulty understanding or appreciating these sorts of changes, compared to what they might have been used to, and still believe is a "better" way. A discrepancy in values is something that a husband and wife have to work out. It may be quite difficult to come to 
terms on such an issue, but with compassion and understanding, many NDErs do resolve the differences that they have in their relationships with their primary partners.

\section{Relationships with Family Members}

The impact that an NDE has on an experiencer can ultimately affect the relationship with the whole family. The changes in an NDEr's character can alter how he or she relates to the family both in action and in attitude. Most of the subjects in this study found that their family relationships were improved in one way or another. As with relationships in marriages, though, problems do not simply disappear in family relations after an NDE. Some problems are lessened, but there may also be the formation of new difficulties as these relationships go through adjustment to the changes in the experiencer.

Several of the NDErs in this study said that they felt their family relationships had been positively affected, to varying degrees. Mary always had a very close and caring family, but she agreed with her husband and daughter when they commented that they probably have all grown closer after Mary's NDE. She found her family to be quite supportive of her and her experience, accepting it, even if they didn't understand it at first. Furthermore, she made no attempt to pressure any of them into believing it, but through explaining and sharing the experience and the positive impact it had on Mary personally, the family feels it has drawn them all closer together.

Beth also explained that her children have not had much difficulty with her after her NDE, despite her divorce from their father. In discussing the possibility of her children feeling that they were no longer receiving as much attention as before, now that she is more involved with helping others since her NDE, Beth said:

I don't think my kids felt that way. If anything, I became more loving and much more appreciative of who they were; I could really see the beauty in them. Before, I think I was more distant; I wasn't meeting them on the emotional level that I am meeting them on now. When I moved [to where I am now], my two older kids had moved out already, and the 15 year old, his father took custody of him. Now, the two boys, [in their early 20's] live with me... . They like what they're feeling; they like my values. They've begun to express how screwed up their father's values are, and how they don't feel comfortable in his house. They can't communicate with him-the same complaints that I had, 
and they verbalized that themselves. [We can communicate better now, we're more open], and they like who I am now.

Pat also mentioned a more understanding relationship with her children after her NDE. She talked about how before, she might have been more apt to judge or criticize things they did, especially things that she would have thought might have difficult consequences for them. She specifically discussed a hypothetical example of how she feels more accepting and understanding of people, such as her own children, while remaining just as concerned:

[I relate to people differently now], when I see a person, I may look at that person, I'm speaking of children now, and you see a child that you have, and you know that child is doing something that can really be immoral, and it isn't just the fact that you think it may be immoral, but you think of the consequences that can happen. It isn't just because something's immoral, or it's against society, because there are different rules in different societies, but some things that people say are immoral cause physical consequences, and mental consequences for these people, that we see down the road could happen to them. Before I had this experience, I would probably look at that situation, and that would be all I would see. I might be upset at that person, I might try to change that person, I might try to coerce that child to behave in a way I thought was safer for [them]. Now, I look at that person, and I still have those feelings of fear for them, for what could happen to them, mentally and physically. I still have that fear, but I also know that usually they're looking for love.... They have to go through a learning experience. ... and I'm more willing to let them learn at their own rate. ... sometimes that hurts, and sometimes they really get themselves into hot water, that they have years of consequence to have to pay for. I don't condemn them for it anymore. I feel sorry for them, and I love them, and I look upon them as somebody who just doesn't know.... I have more understanding of why they do what they do-a better understanding ... most anything that anybody does, no matter what emotion is behind it, they're looking for love and acceptance.

This reveals how Pat looks at others, and specifically how she might even view her own children, in a different light than before. She now relates to others with more compassionate understanding and acceptance. She believes that behind most people's actions is a desire for love, and that knowing this, she is no longer so critical or judgmental. Despite her own fears of the consequences they might suffer, she feels it is simply where those people are in their development, and that she should therefore let them learn on their own. In talking to Pat, it is 
clear that this hesitancy to interfere is not an indifference to others, or lack of concern. Rather, it is a greater acceptance of them.

This acceptance and understanding of others also led Pat to understand the family that she grew up with better, especially her mother. Pat explained that even though she doesn't feel she can share her experience with her relatives because "there would be no way they could [accept it]," she now realizes that they just have a "limited view." She explained:

I don't see those limits, but I understand that they have to do that to be safe. I just think, boy, when they do leave this body, and they progress on with their life, that they're going to have a wonderful surprise.... I just wish they could know it now ... [but] it will be there.

She does not want to change them, but rather, anticipates their own happiness over what she feels they will eventually learn on their own. Pat also discussed her relationship with her mother, whom she at one time had resentment for, but now loves. Pat explained that her mother had left her to be raised by Pat's grandmother, and that she was at times fairly cruel to Pat. Her mother would see her only during visits, once or twice a year. Pat wanted very much to live with her mother while growing up, and tried living with her twice, but had to move back with her grandmother both times because of the "mental abuse." Pat said:

I suppose of anybody that I would have the strongest negative feelings toward, it would have been this woman. I don't think there is anybody else that I could have felt as badly toward as I did her. I just [came] to hate her, and now, I feel so very sorry for her. I don't feel any hatred, I love her, I really do love her. . . It's an understanding, it doesn't just come with feelings being changed automatically, but an understanding, and when you understand something totally, then the feelings come after that.... The part of her that does the lashing out-of course, she's just looking for love, and she doesn't recognize love no matter how much you give her-she doesn't recognize it anyway, and that's a terrible thing to go through.... I know that once she sheds this, there will be nothing left there but love, but for me it is there already because of what I know.

Pat now looks at her mother with compassion, not concentrating on the side that was so cruel to her as a child. Rather, she is able to see inside her mother, "the pure energy love of God, which has nothing to do with this physical thing," the person who was mean to Pat for many 
years. She believes the behavior is not the inner essence of her mother, being understanding enough to even feel sorry for her mother, despite years of disliking her while growing up. While the relationship is not necessarily better outwardly, for Pat mentioned that her mother still is not very warm or receptive, there is a love and concern Pat has that has drastically changed how she relates to her mother. In her eyes the relationship has been transformed.

Jenny also explained changed feelings toward her family and, to an extent, changes in the relationships overall. Not only does she "take things more in stride than [she] used to," she has had a positive impact on their communication with each other as well. She discussed how her experience influenced her relationship with her family, and how that also changed some of the ways they do things:

Our family is just not terribly communicative, and we're a little more open than we used to be, I think mainly because I pressed people to talk about things, instead of just being quiet.... Before, I would sit back and just say, "This family is really dysfunctional and I'm just going to ignore it because it's never going to come around. ..." Before, we didn't talk about things like.... my younger brother [who is] an alcoholic.... It was like, kind of under the table, and we knew there is a drinking problem. ... I think I'm more aware of what their feel. ings are, and I accept that ... and that's different than it used to be, because, like with my mother, we didn't talk at all, because it was just painful. I mean, we miscommunicated, and we'd argue and I thought she was prying, and she thought I didn't share anything, so we just ended up not talking at all. I think, since then I've-since the experience, there's been more openness-mainly I think, because I take a step back, and I see her differently than I did before.

Jenny's experience led her to be more accepting of her family being the way they are. She does not attempt to change them, but her own openness has resulted in the whole family being more open. She mentions now understanding their feelings better, and specifically being able to relate to her mother better. In this case, it is not so much that her mother may or may not have changed, but rather that Jenny's view of her has changed.

Showing a similar understanding, Sue also remarked that she was able to look at her parents differently than before her experience, saying:

I respect them from where they're coming from, and where [they are] right now. Dad has a lot of serious problems, and he's not willing to admit to any of those, but I respect him for where he's at because I 
know I've had to work through quite a bit myself, but until [someone] wants to change, there's nothing you can do-and Dad's not willing to change. What I've basically done, is been able to talk to him and say things I need to say to him that are helpful, you know, try to be supportive, whatever, but I don't expect him to change. . . I don't argue with him anymore, I just let him be himself as much as I can. I'm not going to sit here and say it's been perfect or anything, because I still get very angry with him. I get upset; I get upset with my mom, too. I get upset with everyone-it doesn't change everything to make it peachy-keen-but it's less often, and not to the degree and frequency. .. I can just basically let him go off and do what he needs to do, and with my mom, [see] where she's coming from, too.

The acceptance that Sue was so impressed with in her NDE has led to her look at others with acceptance also. She explained that she is not trying to change her parents, but accepts for who they are, as she felt total acceptance in her experience. Her parents have not necessarily changed, but the relationship has, at least for Sue, through her greater understanding of them. It is important to note that she does not feel that the relationship never has any difficulties. She admits there are times when she does indeed get angry. NDErs do not become people who are beyond feelings of disappointment or irritation. They may find that they are more understanding - as Sue says, she doesn't get angry as often, or to the same degree-but NDErs are still the same people as before their NDEs in many ways. Relationships may also remain the same, but with greater understanding, they can also at times be more easygoing.

Sue also said that she has found that her contact with her family has decreased. She attributed it to a loss of common interests, saying:

It seems like - and I don't mean to say this in a downgrading way - I've grown. I've grown beyond where they're at. They still sit at home. ... They [always] worked, came home, and stayed in the house. They didn't go out or associate with people, and I've grown. I feel beyond that. That's no more where I want to be, and when Mom calls and tells me all the latest gossip in town, I couldn't really care less. ... .

Sue made it clear that she did not mean this in a judgmental way, but that she is simply no longer interested in the same lifestyle that she had before. She is able to understand that that is the way her parents still are, and that is alright; it just is not what she wants for herself. 
While NDErs often feel that their experiences have a positive impact on their relationships with their family, there may be instances where the NDE can cause some problems as well. Difficulties may arise from the initial reaction to the occurrence of an NDE in the life of a family member, and/or the ensuing aftereffects that may alter an experiencer's relationships with family members.

Ann recalled how her mother reacted to her talking about her NDE as a teenager, and explained that that reaction did affect their relationship to a degree. She said that she had told her mother about her experience right after it happened, and that her mother didn't say anything. After that, Ann decided to not discuss it anymore, but did come to feel that it had an impact on their relationship. She explained:

\begin{abstract}
One of the things [my mother's reaction] did raise for me was, "Have I hit something? Have I hit upon something that I won't be able to talk about with her?" We had been able to talk about so many things. She had a very difficult life, and she had been able to talk about that with me. She had done a lot of very candid preparation for me, of facing adulthood, [talking] ... and [she was] very open-I could ask her anything-and with that reaction, with her reaction to that experience, I wondered if there might be things that we would not be able to talk about.... There was always a question. ... I think there was always a closed door, somewhere in our relationship after that. . . While other things were good about our relationship, there was always this little sort of, I don't know how to say it, "dark" spot, for lack of a better word. That somehow, there was something we still had not been open about with each other. [Do you think that was ever a problem for either of you?] I'm not sure if it was a problem with her. I do think it became a problem with me because, again, I would often-I had wondered at the beginning - "If this is something that I can't talk about with her, will there be other things?" So there was a sense of testing . . . later in my life, as I would raise issues with her.
\end{abstract}

This lack of receptivity on her mother's part led Ann to question the limits of their openness, which may have been uncomfortable at times. Ann went on to mention that she later learned, after her mother's death, that her mother had a concern about insanity in their family, so this concern may have then been the reason she did not want to talk about Ann's NDE. Ann did not feel that her experience had any severe impact on her relationship with her mother, but she did mention that in addition to her having a greater appreciation of her mother, there was one other way in which she thinks the experience might have changed their relationship. Ann explained that after her experience, she lost interest in certain activities, because she simply didn't find 
them very satisfying, and her mother thought this was a bit strange. Ann commented:

I think what happened was she saw me as being very serious, almost too much so. "Old-fashioned" was the way that she described it. She thought that I seemed to exhibit a lot of old-fashioned ideas, in terms of the direction that I took in my life, things that I would agree to or not agree to do with friends. That kind of thing. Things I think that she thought were not typical of being a teenager, and so she would say sometimes, "You're so old-fashioned. I don't understand how you got to be so old-fashioned."

Ann mentioned that she and her mother did have the "typical clashes that teenagers-adolescents-have with their parents," but that her "old-fashionedness" still led her mother to think that Ann "was behaving too old, too sedate for her age." She explained:

I assured her that I enjoyed dating, and that was fine, but I didn't see the need to party excessively with my friends, [or go] on school trips with the exception of the ones that were educational, and she became concerned that I was missing out....

Ann expressed a decreased interest in certain social activities that did not encourage deeper, more meaningful interaction with others after her NDE. She did not express being directly aware of her NDE transforming her personality as a teenager, but did say that she felt she "became more serious about things that [she] was doing in life." This orientation led Ann to have strong ideals about what she felt was important, including people-getting to know and help them. She commented that this was probably a result of her experience. These characteristics in turn were perceived by her mother as being eccentric; in her eyes Ann "was behaving too old."

Some NDErs participating in this study also described some changes in their family relationships after their experience that were more directly perceived by their families as difficulties and problems due to the impact that the NDE had on the experiencer. Jane commented:

The main thing that's happened [as far as a problem] is I'm too involved with other people-too busy with church, and volunteer work, doing this and doing that, and sometimes [my family] gets kind of angry about that -"Hey Mom, don't forget about us!" that kind of thing-but it's really not a serious problem. 
Jane explained that this has not created any great difficulties, saying that, in fact, her family finds she is generally more easy going, and that "if [her relationship with her children and husband] has changed at all, it is just deeper, better - because of sharing [her experience] with them." She mentioned that one of her children is writing a paper on the NDE, and that talking about it has brought them all closer, helping them to understand her better. Further commenting on her relationship with her family, she said:

\begin{abstract}
As far as with my family, I still lose my temper and yell: I'm trying to raise two teenaged girls, but there is still a difference. I'm definitely more understanding.... [and] relaxed, not as uptight. I'm a perfectionist, and always have been, and it's really hard to not expect a lot. I still expect a lot-I do from myself and I do from those around me. The difference is that when you don't live up to my expectations, or my standards, it's okay. ... Oh, there are times, you get behind in your work, you get kind of anxious, but as far as everyday living, I'm much more, just overall, easier going.
\end{abstract}

Jane feels that her relationships are closer after her NDE, but she also pointed out that she is not a completely different person. She still has some of the same character that she had before her experience; she may still get angry, or have concerns over her work: life did not suddenly become perfect. Overall, though, Jane commented that she feels she relates to others with greater understanding.

Dorothy also said that she is able to understand and accept her family better, but added that it can still be difficult for them to understand her. There are times when her husband and children do not understand her going so far out of her way to help others, giving others so much concern and attention. She discussed how she tries to handle this:

I've told my husband and told my family, "I have to do this, and you have the choice: you can either love me in spite of whatever you think that I'm either right or wrong with, and if you think I'm heavily wrong, pray for me. Right or wrong, I have to do it.". ... It's not easy to explain ... you have to hope that with time they will understand better. ... I don't know what to do with a person who doesn't really understand it. ... One [of my children] told me that if I have anything more to do with AIDS patients... I'll never be around my lgrandchildren] again. That's tough, but I still deal with AIDS patients. What do I give up and what do I keep?

It can certainly be frustrating for an NDEr to deal with family members who are not able to understand or accept what he or she does. 
As Dorothy pointed out, her family has difficulty with her actively helping others. However, she feels strongly enough about what she does that she simply tries to explain and hopes they eventually understand that this is of great importance to her. Again, she stressed the importance of being very understanding, and not critical, of their views, but admitted she is still compelled to do what she feels she has to do.

John has also found that his family sometimes has difficulty with his helping others through his volunteer work:

Yeah, they get jealous sometimes. I try to explain that it in no way means that my love or concern for them has diminished, just because I'm never home or never see them. That sounds a little hypocritical. I think it is particularly hard on my son, who is the youngest member of the family, because, "Here you are, going around loving the world, but what about me?"

Like Dorothy, John found that his family occasionally finds it troubling that he spends so much of his time working with others. It is often frustrating for NDErs who feel a greater love for everyone, including family, to find that their family may interpret their concern for others as a lack of love for those at home. Difficulties can also arise when the NDErs' role in the family system changes, as they devote more time to other matters and interests. John, for example, spends many hours each week volunteering, and is going to be leaving his present position, teaching at a university, to go into the ministry. These sorts of changes may disrupt the familiar operation of the family unit. Furthermore, the kind of love that the family may expect is often the more personal love, whereas NDErs may have unconditional concern for everyone, so they are not only genuinely concerned about those close to them, but others as well. This is difficult to explain to one's family, as is the very concept of unconditional love. As John commented, "NDErs make statements which are baffling and threatening to non-experiencers, such as 'I don't care about my own life, all I want to do is help other people!' To a family, this is scary."

Cathy found that her husband and children have not had much difficulty after her experience, although she commented that their thinking that it is all "a bit too weird" may sometimes affect how they relate to each other. She explained:

They probably think that I'm hesitant to open up and invite them into my world, of my experience, and who I've become. [But do you think that they necessarily want you to talk about it more?] No, [laughs], 
that is the kind of see-saw we have to play with each other it appears. They're willing at times to go a little bit into my world, and I have to be able to read them enough to know how far to let them in without totally alienating them, so that they won't ever want to come any closer. It seems that the eleven year process has been one of allowing them in when they want to come-making myself available and sharing and talking with how much they're able to take in. I don't want to force anything on them. . . This whole thing sounds too weird, too far out [to them]. . . . I think there's still some resistance too; they want to be comfortable with the person they grew up with. I don't know that they have difficulty with the way that I am now, no, I wouldn't say that, because it has been a lot easier for them after the change. Before my experience, I was pretty judgmental, critical-wanted things my way. I was very perfectionistic, and so it was not easy living with somebody like that, but after the experience, I kind of relaxed a great deal.

Cathy pointed out that this has not really caused any major problems for anyone; she has simply had to become used to how she shares aspects of her experience with her family. The NDE is of great importance to her and her life, so it has taken time to learn how to handle all of the instances that could be difficult for her family, because they are not quite comfortable with such a change. She would like them to know more about it and to accept it but has no desire to force them, accepting that they are just not completely at ease with it all, and prefer to have the "familiar" family, as before the NDE. Cathy mentioned one incident that illustrated how her family's relationships may have been influenced by her NDE. She discussed how her NDE has affected her in a way that she feels helped her and her family, when their home burned down a few years ago and they lost everything. Cathy felt that before her NDE she would have been quite upset about the loss, but that, "as it is, the family got out alive... and that was the most important thing." She explained the perspective that she kept on things, and how that affected her role in the family during a time of crisis:

I've found that one of the greatest things to happen is the inner peace I have, following the experience, and that peace helps me to deal with my outer world in a wonderful, beautiful way. Most people would have felt as if they were drowning in a sea of turbulent waters [if their house had burned down, but] I feel as though I've simply jumped into a stream and I'm floating ... and don't know where I'm going. My husband took it very hard, and I was peaceful, [which was very helpful to the family]. Some people have said that I exuded a lot of strength, if you will. I don't know if it was strength, as it was this tremendous peace in knowing that absolutely everything was going to work out. 
My children and my husband saw that they didn't have to worry about me ... the roles were reversed in that case. I was the one who was directing and overseeing a lot of the things, with the insurance company, and normally those are things that I would not do. I can't handle things like that normally, but in that instance, I did. . . . I was reassuring to my husband-very comforting to [my family, by emphasizing the positive]. I won't be so arrogant to say that I totally made them feel $100 \%$ "Oh, it's okay!" but I know that I made a big impact on them, in pointing out a lot of things, and they agreed that the only thing important was that we got out alive, and that we're all safe and everything. I was able to take care of my husband ... and it felt good for me to be able to be in that position, because usually it's the other way around. ... I would have been bananas before, if it had happened before the experience-they would have been the care-givers. [Was it ever difficult for your family, being that you were not as concerned about the losses?] No, surprisingly no, because I think what I did was I validated their feelings about their loss. I let them know that it was okay for them to grieve over what they had lost, rather than trying to say, "Oh well, that doesn't matter." If it did matter to them . . . it would have been inappropriate for me to gloss that over and say, "Well, forget it. . . ." I validated how [they] felt about that, and I let [them] know that I cared genuinely about [their] feelings.

The inner peace that Cathy's NDE gave her has thereby influenced how she functions as a member of her family. In this instance, she described taking on a new role to help the family cope with a crisis situation. While this does not appear to have been a problem for Cathy and her family, it is possible that this sort of change in responsibilities could be difficult for some families to adjust to. For some, the comfortably familiar dynamics of family relationships may be upset by such a change in roles, causing even further upheaval and distress.

Most of the NDErs in this study felt that their family relationships were in one way or another improved by the impact of their experience. They reported finding themselves to be more caring, understanding, and able in their dealing with their families. Others expressed a belief that their family relationships had been deepened through the mutual sharing and understanding that came with the adjustment to the impact of the NDE on the experiencer. However, changes in the NDEr could have not only positive but also negative implications for family relationships; the family may have difficulty accepting and/or understanding the experience itself, as well as the ensuing aftereffects. A family could conceivably feel very uncomfortable when the accepted mechanics of interaction are altered, giving way to redefined and unfamiliar roles. Several experiencers commented that their families were at times troubled with their new concern for so many other 
people. Others found that their spouses could not cope with the NDEr's transformation. In any case, all of the NDErs interviewed commented that they truly felt that they were more understanding and caring of their family members, even in situations where the relationships encountered difficulties.

\section{Discussion}

It is apparent that the NDE has a profound influence on the lives of those who experience them. Those NDErs who were interviewed for this study all commented on the transformative effects that their experiences have had on them, thereby influencing their subsequent relationships. These NDErs also pointed out, though, that while they feel the experience has been a positive influence on their characters, they are in many ways still the same persons they were prior to their experiences. Their lives have not become trouble-free, despite their new attitudes and interests. However, they were unanimous in their feelings that their lives are now deeper and more satisfying.

They now tend to believe that they are not only more loving, but also more accepting of others, and that they now place greater emphasis on their relations with others. While NDErs often feel that the impact of their NDEs has an enriching effect on their relationships, they do find that some of their relationships encounter difficulties as well. The meaning of an NDE can indeed be so strong that it becomes a significant aspect of who an experiencer comes to feel he or she is; but at the same time, it is often incomprehensible to others. Thus, other people may occasionally be frustrated in their relationships with an NDEr, unable to understand or accept the meaning that the experience has for the NDEr.

William James (1929) wrote that mystical states are absolutely authoritative for those who have them, not authoritative for those who do not have them, and challenge the authoritativeness of ordinary consciousness. These considerations may certainly be a fair assessment of the situation that NDErs at times find themselves in.

After an NDE, relationships within a family may inevitably change, through the reactions and adjustments of others to the NDE and its impact on the experiencer. Some found that their families were quite accepting and supportive of their NDEs. A few of the experiencers explained that their families needed to go through some initial adjustment to understand the NDE and its implications, but that they were able to share the experience openly relatively easily. In these instances, there did not appear to be any obvious reasons why the 
adjustment was simpler than in other families, other than the patient concern and acceptance from family members. These families acknowledged or even embraced the meaning that the NDE had for the experiencer, thereby deepening the relationship for everyone involved.

For other experiencers, the integration of their NDEs into their family lives was not always so easy. Several found that while their families were accepting of their changes in character, they were still frustrated with various aspects of the experiencers' behavior. Some families were disturbed simply by discussion of the experience or related matters. Other families were critical of the new concerns that the NDEr had for so many other people or interests.

It is understandable that a social system such as a family might undergo difficult adjustments as the previous norms of behavior and roles are changed. The most difficult adjustments were in those relationships where the family of the NDEr could not accept the transformation that had taken place in the experiencer's personality.

A few NDErs remarked that their spouses could not cope with their radical changes, or that they and their spouses came to have such dissimilar values and interests that the relationship no longer had mutual bases for continuation. In these instances the relationships were eventually terminated. The very possibility of a strong negative reaction specifically led some NDErs in this study to avoid discussing their experience with others at all. Even in these cases, though, these NDErs remarked that the relationships had been affected by their experiences. They pointed out that they now viewed their families differently, and were more understanding and accepting of them, even though they might wish they could have shared their NDEs.

Despite any of the problems that these NDErs encountered in their family relationships, they all expressed a compassionate understanding of the other members of their families. They did not look down upon them in critical judgment; rather, they showed a sense of acceptance for those persons and the changes that their relationships with one another might have to undergo. NDErs tended to feel better about their family relationships, commenting that the difficulties they encountered were often ordinary family dynamics.

\section{Conclusion}

This study is a rich source of qualitative data on the impact of an NDE on family relationships, but one should be cautious in generalizing due to the small and nonrepresentative sample. Further re- 
search into the impact of an NDE on the experiencer and his or her social interactions is needed, for it is a highly complex matter. Moreover, this is of importance because of the implications it can have for all of the NDErs' social ties.

When people are dramatically transformed by an experience such as an NDE, all of the social systems they are a part of can be affected. Not only are their relationships with family and friends influenced, but also those with people they interact with on a more casual level. The experience may have an impact on relationships with colleagues, neighbors, or even strangers. Therefore, further in-depth exploration of these matters is indicated, especially considering the fact that this field of study is still in its formative stages.

Future research could start with more intense study of NDErs who have already participated in past studies. This would certainly yield fruitful data and be an easily obtained sample. In-depth interviewing might also be supplemented with longitudinal studies to monitor the evolution of an NDE's impact on social relationships. The inclusion of NDErs who have not had much contact with previous research is admittedly not as simple to arrange, but is worthwhile, not only for the expansion of the sample, but also for the lack of familiarity that these informants would have with the body of already amassed research, which can create expectations and bias. The inclusion of more "nontraditional" samples might also shed more light on the nature of social interaction after an NDE, such as Flynn's case study of "A Former Gangster's Transformation" (Flynn, 1986, pp. 41-44).

The collection of data from those who interact with NDErs would also be beneficial. While one interview in this study did have members of the experiencer's family present, this avenue of data collection was beyond the scope of this study. Ring (1984), however, attempted to explore this source of data by asking some of his subjects to distribute a written "Behavior Rating Inventory" to persons who knew them well. Although the sample size of returned questionnaires was admittedly small, Ring found that those data indicated "... that overall, the changes that the NDErs attribute to themselves are also perceived and corroborated by individuals who knew them well (and, presumably, usually best) both before and after their experience" (Ring, 1984, pp. 140-141). Attempts such as these to obtain more information from those in contact with NDErs, could provide great insight into not only changes in personality, but also relationships.

Future research might also consider the mutual benefits of considering a comparison of the impact of an NDE on interpersonal relationships with other social behavior. Research into other sociological and/ 
or social psychological topics, such as family relationships, divorce, friendship, helping behavior, and social deviance, might be of worthwhile comparison for understanding more about an NDEr's social interaction. Conversely, research into the impact of an NDE on an experiencer can certainly be of use to those studies. Learning more about how experiencers' relationships change as they cope and adjust can assist and expand upon research into the systems of families and friendships. Perhaps understanding NDErs, who may feel so positively about something and yet not feel able to share it with those closest to them, might also broaden conceptions of social deviance. The widespread applicability of any increased understanding of social interactions merits further research into these matters of the near-death experience.

\section{References}

Atwater, P.M.H. (1988). Coming back to life: The after-effects of the near-death experience. New York, NY: Dodd, Mead.

Bowlby, J. (1961). Process of mourning. International Journal of Psychoanalysis, 42, 317-340.

Flynn, C. P. (1982). Meanings and implications of NDEr transformations: Some preliminary findings and implications. Anabiosis: The Journal of Near-Death Studies, 2, 3-14.

Flynn, C.P. (1986). After the beyond: Human transformation and the near-death experience. Englewood Cliffs, NJ: Prentice-Hall.

Harris, B., and Bascom, L. (1990). Full circle: The near-death experience and beyond. New York, NY: Pocket Books.

James, W. (1929). The varieties of mystical experience. New York, NY: Random House. Moody, R.A., Jr. (1988). The light beyond New York, NY: Bantam Books.

Ring, K. (1984). Heading toward omega: In search of the meaning of the near-death experience. New York, NY: Morrow.

Thomas, W.I., and Thomas, D.S. (1928). The child in America. New York, NY: Knopf.

Vernon, G.M. (1970). The sociology of death. New York, NY: Ronald Press. 